\title{
Challenges Facing Older Adults during the COVID-19 Outbreak
}

\author{
Eqbal Radwan ${ }^{1,2 *}$, Afnan Radwan ${ }^{3}$, Walaa Radwan ${ }^{4}$
}

${ }^{1}$ Biology Department, Islamic University of Gaza, PALESTINE

${ }^{2}$ Directorate of Education-East Gaza, Ministry of Education and Higher Education, PALESTINE

${ }^{3}$ Faculty of Education, Islamic University of Gaza, Gaza Strip, PALESTINE

${ }^{4}$ Faculty of Education, Ummah Open University, Gaza Strip, PALESTINE

*Corresponding Author: ernp2030@gmail.com

Citation: Radwan, E., Radwan, A. and Radwan, W. (2021). Challenges Facing Older Adults during the COVID-19 Outbreak. European Journal of Environment and Public Health, 5(1), em0059. https://doi.org/10.29333/ejeph/8457

\section{ARTICLE INFO}

Received: 8 Jun. 2020

Accepted: 22 Jul. 2020

\begin{abstract}
As COVID-19 rapidly spread at the globe, it has attracted significant attention and brought unprecedented efforts, resulting in stops of routine activities and changes in day-to-day behavioral patterns of the public. To mitigate its impact on health bodies and systems, societies, and economies, many countries have adopted nonpharmacological preventive procedures such as social or spatial distancing, using protective gloves and masks, as well as frequently handwashing; these have been extensively implemented. However, preventive procedures aimed at protecting the healthcare systems have side-effects that might have a big impact on the elderly's life. In this article, we highlight the main challenges facing older adults during the outbreak of the COVID-19 pandemic. Despite the importance of preventive measures in the protection of elderly health and containing the outbreak of COVID-19, they will undoubtedly have short and long term consequences for the wellbeing and mental health of the older adults.
\end{abstract}

Keywords: COVID-19, older adults, well-being, social distancing, social disconnectedness, isolation, preventive measures

\section{INTRODUCTION}

The coronavirus disease 2019 (COVID-19) has rapidly spread all over the world, posing significant economic, social, health and environmental challenges to countries (Radwan and Radwan, 2020a; Radwan et al., 2020b; Cohen, 2020; El Baz and Imziln, 2020; Ajari, 2020; Ajari, 2020). Since the first case of novel coronavirus disease 2019 was detected in December 2019, in Wuhan (Hubei, China), it has attracted significant attention resulting in stops of daily activities and changes life patterns of the public. Till now, there are no proven vaccine and drug treatments (Li and De Clercq, 2020), so adherence to non-pharmaceutical practices, as repeated handwashing, covering the nose and mouth when coughing/sneezing, and maintaining spatial separation between people, are essential to contain the spread of the virus and mitigate the burden of the disease (Adalja et al., 2020). The measures of "social distancing” include the closure of workplace, homecare, and educational institutions, avoided mass gatherings, isolation of confirmed and suspected cases, quarantine of people in contact with confirmed and suspected cases, and stay-at-home (ECDC, 2020). Besides these measures, additional procedures have been implemented to protect older adults from this great risk.
In spite of the role of applied preventive procedures in slow the rapid outbreak of COVID-19 and the protection of the physical health of the elderly, they will undoubtedly have short and long term consequences for the psychological well-being and mental health of the older adults. Therefore, great and unprecedented efforts must be immediately taken into consideration to address the influence of the outbreak of COVID-19 on the general health of the individuals, particularly the older adults (Cao et al., 2020; Xiao et al., 2020; El Baz \& Imziln, 2020). Governmental interventions adopted by responsibility authorities have aimed at the protection of the physical health of populations especially people at higher risk including the older adults. However, social distancing accelerates the spread of misinformation and can have dangerous consequences for psychological wellbeing in the elderly (see Figure 1).

In the last several days, the total number of cases with 2019 novel coronavirus disease (COVID-19) and the number of associated deaths has been rapidly increasing around the world. Most of the death cases by COVID-19 were older adults. The older adults in some countries accounting a considerable proportion of the total population, therefore, the rapid outbreak of COVID-19 and high death rate could worsen psychiatric symptoms of older adults, and increasing the risks of mental health problems (Galea et al., 2020). 


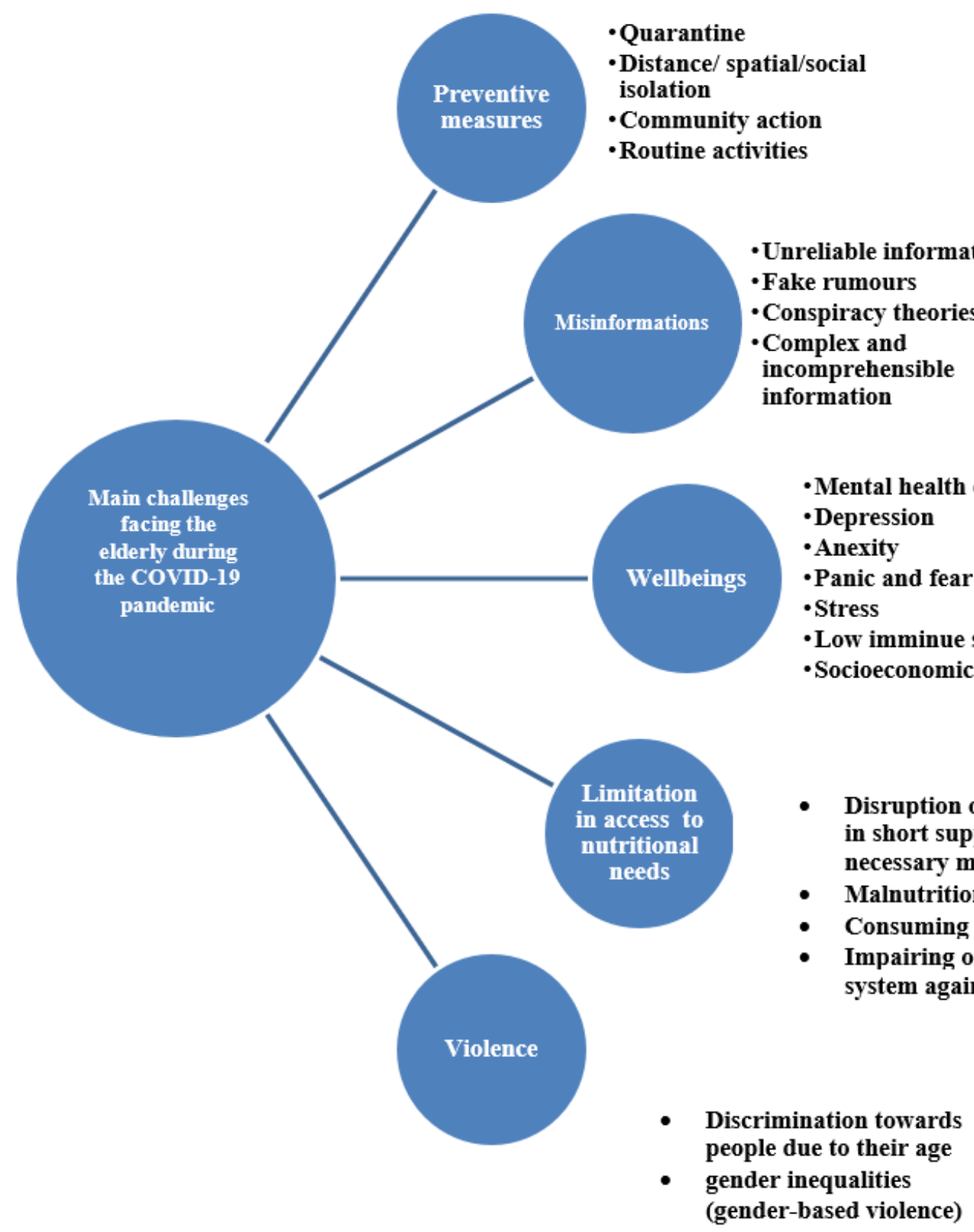

Figure 1. Main challenges facing the elderly during the outbreak of the COVID-19 pandemic

\section{PREVENTIVE MEASURES}

During this critical time, many countries enforce preventive measures including social isolation, lockdowns, and curfews to contain the outbreak of the COVID-19 pandemic. The older adult was told to self-isolate and stay home for a long period of time to protect them from infection and mitigate the spread of COVID-19. Social distancing can minimize the wellbeing of the elderly given the dire situation posed by the COVID-19 pandemic. Recently, the experts have recommended replacing the term "social distancing" to "spatial distancing", due to avoid misleading (Abel and Mcqueen, 2020). "Spatial distancing” or "Spatial isolation" refers to maintaining the physical distance from others that the use of "social distancing" intends to promote. But adherence to spatial distancing can have the side-effect of a social distancing that can have profound consequences for psychological wellbeing the elderly (Xiao et al., 2020).
It is well known that impose of quarantine and social isolation among older adults is considered a severe concern that affected mental health because of their increased risk of cardiovascular, neurocognitive, autoimmune, and mental health problems (Gerst-Emerson and Jayawardhana, 2015). More recently, it was reported that social isolation and disconnectedness puts older adults at greater risk of anxiety and depression (Santini et al., 2020). These effects will be high severed for the elderly whose social contact is only out of the home, such as at community centers, daycare clinics, and places of worship. Older adults who do not have close relatives, and greatly depend on social support from out of the home could be subjected to additional risk, along with those who suffer from loneliness and isolation. Therefore, urgent procedures should be implemented to mitigate the mental health consequences for older adults when they were instructed to stay home and avoid social contact with others. 
During the outbreak of COVID-19, public activities have been suspended to minimize the risk of COVID-19 transmission; thus, online services, especially mental health services, have been adopted. Online technology, especially social media, plays a key role in providing social support and a sense of belonging throughout the enforced isolation. In addition, online interventions could be made with members of the family, relatives, friends, health-care professionals, voluntary organizations, or community outreach institutions. Providing behavioral and psychological consulting through the platforms of the internet help older adults to mitigate loneliness and improve their mental health (Duan and Zhu, 2020; Käll et al., 2020; Liu et al., 2020; Radwan et al., 2020a). During social isolation and social distancing, modern communications as well as using the various internet platforms can be used to ensure social interactions of the elderly with the others.

Some older adults have limited access to different internet services and to use modern communications, therefore, a small fraction of older adults can employ and benefit from these services (Yang et al., 2020). In addition, clinically stable older adults who suffered from psychiatric disorders need to visit psychiatric clinics to obtain the required treatments. The movement restrictions have become a major barrier to access medicines for this group. The mental health services for older adults face great challenges in the time of the COVID-19 outbreak. In some countries, attention paid to these vulnerable people seems to be inadequate respecting psychological services. Therefore, health policymakers should collaborate to overcome this barrier and provide older adults with high-quality psychological services.

The current status in very low, low and middle-income countries maybe even worse. In many countries, the proportion of older people is the lowest when compared to other categories, but socioeconomic conditions and weaker health systems could be exacerbated consequences of the pandemic and increase the risk of the outbreak of COVID-19 among the elderly. The elderly could be bear high burdens caused by the inaccessibility of timely healthcare services and accurate information that impose poor health upon them.

\section{MISINFORMATION}

Misinformation not only refers to the inaccuracy of information, but it can also come from the torrent of information presenting from non-specialists. Misinformation may lead to suspicion, distrust, and uncertainty as well as to increases the risk of feelings of anxiety, insecurity, and emotional tension, all of which may impair the quality of the elderly life.

Anxiety resulting from the uncertainty of information about the COVID-19 can lead to trigger the onset of psychiatric disorders and could increase rates of suicide (Tucci et al., 2017). During the outbreak of COVID-19, misinformation also creates a sense of uncomfortable and insecurity. Statements underestimating the severity of the disease (e.g., 'it is just a flu') and downplaying the risk that young person's run (e.g. 'it only kills old people'), could have strongly participated to the rapid outbreak of the COVID-19.
The outbreak of the COVID-19 pandemic has opened up different problems including misleading rumors, the lifeendangering consequences of supposed cures, and conspiracy theories about the origin of COVID-19. Misinformation and dangerous rumors circulated the world and thus paired with racism and mass fearmongering all closely linked to the new "Infomedia" systems of the present century characterized by the multiplicity of means of communication between the elderly. Some people have reported false claims because they failed to think about whether the content was reliable. The sharing and posting of misinformation have a harmful influence beyond the immediate risk of the COVID-19 itself. On the internet, many misinformation were seen related to 'treatments' that are not proven, techniques to prevent exposure and infection that are either not proven and/or filled with a lot of misleading information, and instruction for individuals to stock up on supplies and food. These rumors contributed to spreading panic among the public especially the elderly (Radwan and Radwan, 2020b).

To reduce misinformation and fake rumors among the elderly, news broadcasts should be more concise, clear, and inclusive, add languages like sign language, and use various channels including newspapers, radio, television, landlines, and mobile apps. Information should be communicated in simple language that is understandable by the elderly, no matter her or his educational level (Buchanan, 2020). Complex terms and neologisms related to COVID-19 (eg, social distancing) should be replaced with simple terms and giving practical advice relevant to life. For example: 'you should go to the market only once a week and keep enough distance between you and others and avoid touch them'. Countries can also corporate with non-governmental associations to establish initiatives that help the elderly and promote the changes in their lifestyle.

\section{WELLBEING}

Wellbeing is considered a key concept to support and facilitate the mental health of the elderly. Caring for the wellbeing of the elderly is not limited to preventing the incidence of mental health disorders. It is well-known that the immune system is strongly affected by stress and other psychological disorders. In addition, the loss of life satisfaction, increases in the expression of negative emotions, and the reduction in the expression of positive emotions are related to higher levels of inflammation, which increases the risk of contracting with different diseases (Fancourt and Steptoe, 2020; Newman and Zainal, 2020). For this reason, experts are making important recommendations that can enhance the mental health and overall wellbeing of older adults.

During the isolation period, it is very important to find creative ways that maintaining affective, meaningful, and social links with the elderly. Procedures for doing this can be not only technological; some elderly adults in care homes may not access to the internet and using modern communication devices, this necessitates the provision of social support to this group. Collaborative community action to mitigate the psychological effect of social isolation is thus even of 
significant importance. In spite of imposed strict measures, care homes could risk continuing safe social activities among the elderly to avoid the greater risk of impairing the status of the health of the population. To minimize anxiety resulting from overexposure to news, experts advise the elderly to depend on the reliable sources of up to date information related to COVID-19. The access of the elderly to the news should be restricted and directing them to reliable sources and keeping them away from false rumors that can destroy their mental health.

With regard to the provision of urgent services in the emergency times, healthcare systems should use telemedicine to protect the elderly from getting infected, effectively provide mental health services, and ensure access to the different means of communication by the older adults. Health care systems should be attentive offering online psychological assistance or via telephone and urging the elderly to use mobile apps to provide counseling or treatment during the isolation period (Lai et al., 2020; Xiang et al., 2020). A specialized team should be prepared and then trained in various psychosocial skills and diagnosis of psychiatric disorders (Ho, 2020).

We call upon all public health bodies, academics, specialists, researchers, and policy-makers to support communitarian strategies that interest with the wellbeing of the elderly especially those who are often overlooked. All members of the community should share responsibility towards older adults. Through cooperation, the long-term solutions will be achieved to the COVID-19 pandemic.

Although, isolating the older adults contributes to reducing transmission and minimize the spread of the COVID19 among the population, but this effect could be great consequences on the older adults, who should be urgently targeted besides the implementation of preventive strategies.

\section{LIMITATION IN ACCESS TO NUTRITIONAL NEEDS}

While all groups of populations are affected by the COVID19 pandemic, the older adults are at the greatest risk. The outbreak of the COVID-19 pandemic has resulted in the disruption of food supply and unavailable or in short supply of adequate necessary materials (e.g. drugs, food supplements, healthy foods..etc.), this leads to the vulnerable of the older adults to malnutrition and consuming non-healthy foods (WHO, 2020a).

According to the previous studies, malnutrition is common among older adults, with studies reporting malnourishment in $35-65 \%$ and $25-60 \%$ of elderly hospitalized patients and institutionalized older adults respectively (Posner et al., 1993; Guyonnet and Rolland, 2015). The nutritional status of older adults has considered an indicator of resilience against destabilization (Cobb, 2001). The ecology of adversity and resilience shows that malnutrition can lead to long-term effects that are linked to health (Yousafzai et al., 2013). Indeed, the poor quality of foods has been associated with physical and mental health (Hislop et al., 2006).
The overconsumption of diets high in sugars, refined carbohydrates and saturated fats at the globe contribute to the prevalence of type 2 diabetes and obesity, and could place the elderly, at an increased risk for infected with the COVID-19 and then death in the sever case (Butler and Barrientos, 2020). The overconsumption of non-healthy foods impairs immunity and activates the innate immune system, leading to chronic inflammation and impaired host defense against viruses.

The psychological and behavioral countermeasures of older adults are important determinants to enhance resilience and improve the efficacy of public health approaches to contain the COVID-19 pandemic (Reissman et al., 2006). Due to these risks, access to healthy foods should be taken into consideration and the older adults should be mindful of healthy eating habits to minimize long-term complications from COVID-19. Therefore, nutrition experts recommend the older adults refrain from consuming foods rich in sugar and saturated fats, and instead eat significant amounts of whole grains, fiber, unsaturated fats, and antioxidants to boost immune function (Connaughton et al., 2016).

\section{VIOLENCE}

Implemented preventive measures to contain the COVID19 outbreak mean that the older adults will spend more times in their homes. The home, however, is not always a safe place for older adults who are experiencing or are at risk of abuse. Reports reveal that violence can increase during and in the aftermath of the outbreak of diseases including the COVID-19 pandemic (Peterman et al., 2020). Violence against older adults (e.g. psychological, physical, and sexual violence, neglect, and financial abuse) can have damaging consequences and can even lead to death. More recently, it was reported that violence against older adults has risen sharply during the COVID-19 pandemic and imposition of lockdown procedures (Sajan, 2020). During the COVID-19 crisis, older adults facing violence in their homes, long-term care homes, and online with a surge in scams (WHO, 2020c).

The preventive measures imposed during the COVID-19 pandemic exacerbate the factors which put older adults at risk of violence (Storey, 2020). Discrimination towards people due to their age has increased the risk factor for violence against older adults during the COVID-19 crisis (Trabucchi and De Leo, 2020). For older women, prolonged exposure to their abusers as well as gender inequalities has worsened the risks of genderbased violence against them (Han and Mosqueda, 2020). In many countries influenced by the COVID-19 pandemic, records indicate an increase in the cases of domestic violence, in particular older women maltreatment (UN Women, 2020; Sajan, 2020). Although reports on violence during the COVID19 crisis are very scarce, established evidence on family violence against older adults reveals that various risk factors are likely to be exacerbated during the time of the COVID-19 pandemic (Eisner and Nivette, 2020; Storey, 2020).

During this critical period, it is very important to find creative actions to address violence in the home during the COVID-19 pandemic. To ending violence against older adults in homes or other places such as home care and a healthy 
workplace, the WHO (2020 c and d) recommended to imposed some procedures as follow:

- Enforce measures of accountability for any perpetrators of violence against older adults.

- Ensure that residential for older people are more closely monitored by responsible authorities.

- Increased awareness of the harmful effect of violence against older adults and present information via TV, radio, and various platforms of social media on how older adults can receive support and help safely.

- Create and extend national helplines for violence against older adults in particular older women.

- In the case of violence and abuse towards the elderly, allow them to leave and change their residence during the restriction of movement.

- Collaborate with different sectors (such as social and health services) to address violence against older adults, by establishing virtual teams that can provide support in the right time.

\section{REFERENCES}

Abel, T. and Mcqueen, D. (2020). The COVID-19 pandemic calls for spatial distancing and social closeness: not for social distancing! International Journal of Public Health, 65(3), 231-231. https://doi.org/10.1007/s00038-02001366-7

Adalja, A. A., Toner, E. and Inglesby, T. V. (2020). Priorities for the US Health Community Responding to COVID-19. Jama, 323(14), 1343. https://doi.org/10.1001/jama.2020.3413

Ajari, E. E. (2020). Why Menstrual Health and Wellbeing Promotion should not be Sidelined in Africa's Response to COVID-19. European J Env Pubi, 4(2), em0045. https://doi.org/10.29333/ejeph/8278

Buchanan, J. (2020). Protect Rights of People with Disabilities During COVID-19, Human Rights Watch, New York.

Butler, M. J. and Barrientos, R. M. (2020). The impact of nutrition on COVID-19 susceptibility and long-term consequences. Brain, Behavior, and Immunity. Brain Behav Immun, 87, 53-54. https://doi.org/10.1016/j.bbi.2020.04. 040

Cao, W., Fang, Z., Hou, G., Han, M., Xu, X., Dong, J. and Zheng, J. (2020). The psychological impact of the COVID-19 epidemic on college students in China. Psychiatry research, 287, 112934. https://doi.org/10.1016/j.psychres.2020.112934

Cobb, T. D. (2001). Reclaiming our food: how the grassroots food movement is changing the way we eat. Storey Publishing, Adams, MA, USA.

Cohen, P. N. (2020). The COVID-19 Epidemic in Rural U.S. Counties. European Journal of Environment and Public Health, 4(2), em0050. https://doi.org/10.29333/ejeph/8331

Duan, L. and Zhu, G. (2020). Psychological interventions for people affected by the COVID-19 epidemic. The Lancet Psychiatry, 7(4), 300-302. https://doi.org/10.1016/S22150366(20)30073-0
ECDC, European Centre for Disease Prevention and Control (2020, March 23). Considerations relating to social distancing measures in response to COVID-19 - second update. Stockholm: ECDC. Available at: https://www.ecdc. europa.eu/sites/default/files/documents/covid-19-socialdistancingmeasuresg-guide-second-update.pdf

Eisner, M. and Nivette, A. (2020). Violence and the pandemic: Urgent questions for research. Harry Frank Guggenheim Foundation. New York. Available at: https://www.hfg. org/Violence\%20and\%20the\%20Pandemic.pdf

El Baz, S. and Imziln, B. (2020). Can Aerosols and Wastewater be Considered as Potential Transmissional Sources of COVID-19 to Humans? European Journal of Environment and Public Health, 4(2), em0047. https://doi.org/10.29333/ ejeph/8324

El Baz, S. and Imziln, B. (2020). Can Aerosols and Wastewater be Considered as Potential Transmissional Sources of COVID-19 to Humans? European Journal of Environment and Public Health, 4(2), em0047. https://doi.org/10.29333/ ejeph/8324

Fancourt, D. and Steptoe, A. (2020). The longitudinal relationship between changes in wellbeing and inflammatory markers: Are associations independent of depression? Brain, behavior, and immunity, 83, 146-152. https://doi.org/10.1016/j.bbi.2019.10.004

Galea, S., Merchant, R. M. and Lurie, N. (2020). The Mental Health Consequences of COVID-19 and Physical Distancing: The Need for Prevention and Early Intervention. JAMA Internal Medicine, 180(6), 817-818. https://doi.org/10.1001/jamainternmed.2020.1562

Gerst-Emerson, K. and Jayawardhana, J. (2015). Loneliness as a public health issue: the impact of loneliness on health care utilization among older adults. American journal of public health, 105(5), 1013-1019. https://doi.org/10.2105/ AJPH.2014.302427

Guyonnet, S. and Rolland, Y. (2015). Screening for malnutrition in older people. Clin Geriatr Med., 31, 429437. https://doi.org/10.1016/j.cger.2015.04.009

Han, S. D. and Mosqueda L. (2020). Elder abuse in the COVID19 era. Journal of the American Geriatrics Society, 68(7), 1386-1387. https://doi.org/10.1111/jgs.16496

Hislop, T. G., Bajdik, C. D., Balneaves, L. G., Holmes, A., Chan, S., Wu, E., Abanto, Z. U. and Butler, A. L. (2006). Physical and emotional health effects and social consequences after participation in a low-fat, high-carbohydrate dietary trial for more than 5 years. J Clin Oncol, 24(15), 2311-2317. https://doi.org/10.1200/JCO.2005.04.3042

Ho, C. S., Chee, C. Y. and Ho, R. C. (2020). Mental health strategies to combat the psychological impact of COVID19 beyond paranoia and panic. Ann Acad Med Singapore, 49(1), 1-3.

Käll, A., Jägholm, S., Hesser, H., Andersson, F., Mathaldi, A., Norkvist, B. T. and Andersson, G. (2020). Internet-based cognitive behavior therapy for loneliness: a pilot randomized controlled trial. Behavior therapy, 51(1), 54-68. https://doi.org/10.1016/j.beth.2019.05.001 
Lai, J., Ma, S., Wang, Y., Cai, Z., Hu, J., Wei, N., ... and Hu, S. (2020). Factors associated with mental health outcomes among health care workers exposed to coronavirus disease 2019. JAMA network open, 3(3), e203976-e203976. https://doi.org/10.1001/jamanetworkopen.2020.3976

Li, G. and De Clercq, E. (2020). Therapeutic options for the 2019 novel coronavirus (2019-nCoV). Nature Reviews, 19, 149-150. https://doi.org/10.1038/d41573-020-00016-0

Liu, S., Yang, L., Zhang, C., Xiang, Y. T., Liu, Z., Hu, S. and Zhang, B. (2020). Online mental health services in China during the COVID-19 outbreak. The Lancet Psychiatry, 7(4), e17-e18. https://doi.org/10.1016/S2215-0366(20)30077-8

Newman, M. G. and Zainal, N. H. (2020). The value of maintaining social connections for mental health in older people. The Lancet Public Health, 5(1), e12-e13. https://doi.org/10.1016/S2468-2667(19)30253-1

Peterman, A., Potts, A., O’Donnell, M., Thompson, K., Shah, N., Oertelt-Prigione, S. and van Gelder, N. (2020). Pandemics and violence against women and children. Center for Global Development working paper, 528. Available at: https://www.cgdev.org/publication/ pandemics-and-violence-against-women-and-children

Posner, B. M., Jette, A. M., Smith, K. W. and Miller, D. R. (1993). Nutrition and health risks in the elderly: the Nutrition Screening Initiative. American journal of public health, 83(7), 972-978. https://doi.org/10.2105/AJPH.83.7.972

Radwan, A. and Radwan, E. (2020a). Social and Economic Impact of School Closure during the Outbreak of the COVID-19 Pandemic: A Quick Online Survey in the Gaza Strip. Pedagogical Research, 5(4), em0068. https://doi.org/ $10.29333 / \mathrm{pr} / 8254$

Radwan, E. and Radwan, A. (2020b). The Spread of the Pandemic of Social Media Panic during the COVID-19 Outbreak. European Journal of Environment and Public Health, 4(2), em0044. https://doi.org/10.29333/ejeph/8277

Radwan, E., Radwan, A. and Radwan, W. (2020a). The Mental Health of School Students and the COVID-19 Pandemic. Aquademia, 4(2), ep20020. https://doi.org/10.29333/ aquademia/8394

Radwan, E., Radwan, A. and Radwan, W. (2020b). Environmental Attitudes of School Students in the Gaza Strip During the COVID-19 Pandemic. Bulletin of Environment, Pharmacology and Life Sciences [BEPLS], 9(6), 85-95.

Reissman, D. B., Watson, P. J., Klomp, R. W., Tanielian, T. L. and Prior, S. D. (2006). Pandemic influenza preparedness: adaptive responses to an evolving challenge. Journal of Homeland Security and Emergency Management, 3(2), 1-24. https://doi.org/10.2202/1547-7355.1233

Sajan, B. (2020). Tenfold increase in elder abuse during COVID19 pandemic, advocates say. Available at: https://bc.ctvnews.ca/tenfold-increase-in-elder-abuseduring-covid-19-pandemic-advocates-say-1.4896176
Santini, Z. I., Jose, P. E., Cornwell, E. Y., Koyanagi, A., Nielsen, L., Hinrichsen, C., ... and Koushede, V. (2020). Social disconnectedness, perceived isolation, and symptoms of depression and anxiety among older Americans (NSHAP): a longitudinal mediation analysis. The Lancet Public Health, 5(1), e62-e70. https://doi.org/10.1016/S2468-2667(19) 30230-0

Storey, J. E. (2020). Risk factors for elder abuse and neglect: A review of the literature. Aggression and violent behavior, 50, 101339. https://doi.org/10.1016/j.avb.2019.101339

Trabucchi, M. and De Leo, D. (2020). Nursing homes or besieged castles: COVID-19 in northern Italy. The Lancet Psychiatry, 7(5), 387-388. https://doi.org/10.1016/S22150366(20)30149-8

Tucci, V., Moukaddam, N., Meadows, J., Shah, S., Galwankar, S. C. and Kapur, G. B. (2017). The forgotten plague: Psychiatric manifestations of Ebola, Zika, and emerging infectious diseases. Journal of global infectious diseases, 9(4), 151-156. https://doi.org/10.4103/jgid.jgid_66_17

UN Women Headquarters (2020). COVID-19 and ending violence against women and girls. UN Women. Available at: https://www.unwomen.org/en/digital-library/ publications/2020/04/issue-brief-covid-19-and-endingviolence-against-women-and-girls

WHO (World Health Organization). (2020a). COVID-19 and Food Safety: Guidance for competent authorities responsible for national food safety control systems.

WHO (World Health Organization). (2020b). COVID-19 and food safety: guidance for food businesses.

WHO (World Health Organization). (2020c). COVID-19 and violence against older people.

WHO (World Health Organization). (2020d). Addressing violence against children, women and older people during the COVID-19 pandemic: key actions, 17 June 2020. In Addressing violence against children, women and older people during the COVID-19 pandemic: key actions.

Xiang, Y. T., Yang, Y., Li, W., Zhang, L., Zhang, Q., Cheung, T. and Ng, C. H. (2020). Timely mental health care for the 2019 novel coronavirus outbreak is urgently needed. The Lancet Psychiatry, 7(3), 228-229. https://doi.org/10.1016/ S2215-0366(20)30046-8

Xiao, H., Zhang, Y., Kong, D., Li, S. and Yang, N. (2020). Social capital and sleep quality in individuals who self-isolated for 14 days during the coronavirus disease 2019 (COVID19) outbreak in January 2020 in China. Medical science monitor: international medical journal of experimental and clinical research, 26, e923921-1. https://doi.org/ 10.12659/MSM.923921

Yang, Y., Li, W., Zhang, Q., Zhang, L., Cheung, T., Xiang, Y. T. (2020). Mental health services for older adults in China during the COVID-19 outbreak. The Lancet Psychiatry, 7(4), e19. https://doi.org/10.1016/S2215-0366(20)30079-1

Yousafzai, A. K., Rasheed, M. A. and Bhutta, Z. A. (2013). Annual research review: improved nutrition-a pathway to resilience. J Child Psychol Psychiatry, 54, 367-377. https://doi.org/10.1111/jcpp.12019 